\title{
Features of distance learning of university students in the context of digitalization
}

\author{
Olga Limarenko ${ }^{1 *}$, Elena Dergach $^{1}$, Sergey Kokhan ${ }^{2}$, Svetlana Romanova ${ }^{3}$, and Luiza \\ Nadeina $^{4}$ \\ ${ }^{1}$ Siberian Federal University, 660041, Krasnoyarsk, Russia \\ ${ }^{2}$ Trans-Baikal State University, 672039, Chita, Russia \\ ${ }^{3}$ Irkutsk State University, 664011, Irkutsk, Russia \\ ${ }^{4}$ National Research Tomsk Polytechnic University, 634050, Tomsk, Russia
}

\begin{abstract}
This article is devoted to special aspects of giving classes in the discipline "Applied Physical Education and Sports" at the Department of Physical Culture at Siberian Federal University. These aspects are considered an example of development and introduction of online course of the swimming specialization in educational process. It is connected with the transition to distance learning caused by the spread of COVID-19 infection in the world. The transition to this format of study was an effective way of interacting with full-time students in the applied discipline. It made it possible to avoid the eventual interruption of educational activities, as feedback from the "student - university teacher" was organized. This allowed the students to receive the full information by providing interim assessment for the spring semester of the 2019-2020 academic year. The article reflects the personal experience of university teachers in the development and implementation of the electronic course, its main resources, content, and features of functioning. This allowed asynchronously teach students, posting interactive lectures, offer videos on the topic of the course, issue practical tasks and training programs, check the assimilation of material, as well as monitor the performance of tasks, maintain motor activity and health of students.
\end{abstract}

\section{Introduction}

The 2019-20 academic year was a tense year due to the threat of COVID-19 coronavirus infection and the emergency transition to distance learning during isolation. It affected the economic, social and other spheres of countries in the world. It also had a global impact on the education system in Russia. All educational institutions, starting from schools, technical schools, colleges and ending with higher education - universities, had to transit to distance learning (DL) $[1,2]$.

According to the Ministry of Education and Science of the Russian Federation, about $80 \%$ of universities were completely able to switch to the online format of working with students in Russia. As for universities subordinated to the Ministry, $100 \%$ of them could

\footnotetext{
*Corresponding author: olga_limarenko@mail.ru
} 
switch to distance learning (based on the materials of the Briefing of the Minister of Science and Higher Education Valery Falkov dated 25.03.2020).

In the context of a pandemic, the transition of higher education to distance learning has created a unique situation. Under the current circumstances, the distance technologies appear to be the only possible ones to use the provision and acquisition of knowledge [3].

Modern university education is going through an era of the large-scale digital transformation. It means that approaches to the structure of the educational process, as well as forms and formats of education are changing. A well-developed online course is one of the attributes of a university's positioning in the educational market.

Digital infrastructure, organizational support from IT specialists, a system for the formation of digital skills and the necessary competencies of a university teacher, as well as the tutor support for training are necessary elements of resource support for distance learning [4].

The forced emergency introduction of the distance format into the educational process among full-time students in many disciplines at many universities was done for the first time. The emergency transition to distance learning has revealed the unpreparedness of many university teachers to give classes using an innovative form [5].

It should be noted that in the course of recent events, the definition of a modern teacher is changing. Today, a modern university teacher is a specialist-teacher in the subject area, who has practical experience, owns modern educational technologies, and has the necessary digital competencies [5].

Analysis of national and foreign theory and practice of distance learning, carried out by a number of scientists headed by S.N. Vodolad [6], allowed to note and form 12 characteristic features which are inherent in distance learning. They are "Flexibility", "Modularity"; "Parallelism", "Long-range action", "Asynchrony", "Coverage", "Profitability", "Teacher", "Student", "NIT", "Sociality" and "Internationality".

As the practice of many universities and the review of literature on various disciplines have shown, the transition to forced online education was not "painful". Universities were ready for a quick transition to distance learning due to the previously developed and timely adapted hardware-technical, software, subject, methodological and administrativemanagement base and support services for DL.

In his study A.V. Ageevets showed the analysis of possible ways of distance learning in disciplines "Physical Culture and Sports" and "Applied Physical Education and Sports" during the educational process at universities [7]. He together with colleagues outlined seven problems and negative aspects when giving classes on the above-mentioned disciplines for students of full-time education in the distance format. They believe that strict control over the materials and forms offered for study at the university is necessary.

The formation of a distance education system, the use of individual elements of the distance education for full-time education, as well as the development of online educational resources are the main directions for the development of digitalization in the higher education system [8].

A fairly large number of studies are devoted to distance learning in higher education. It should be noted that the researches devoted to the transition to distance learning of applied disciplines, by the example of the discipline "Applied physical education and sports", in a forced extreme situation are clearly insufficient.

\section{Materials and methods}

Since March 2020, in the context of a viral pandemic and forced self-isolation of citizens, the educational process at universities should be based on the use of secure online and 
electronic forms of implementation of educational programs (EP), including in disciplines of an applied nature, such as "Applied physical education".

In accordance with the Order of the Ministry of Education and Science of Russia on March 14, 2020 No. 397, on the basis of e-learning with the use of distance learning technologies, work was organized to implement all educational programs at Siberian Federal University (SFU). That's why in the shortest possible time, the structure of distance learning work was developed at the Department of Physical Culture at Siberian Federal University. The most difficult thing was the transition to the distance format in disciplines which are of an applied nature. The discipline "Applied physical education and sports" is no exception. The university teachers of the Department of Physical Culture at Siberian Federal University were able to quickly develop and structure into the electronic format two taught disciplines: "Physical culture and sports" and "Applied physical education and sports". In accordance with students' sport specialization and territorial belonging, 12500 students at SFU were distributed into 45 groups. The university teachers also developed methodological guidelines and tasks for students in each sport specialization.

Having developed electronic courses, the university teachers of the sport specialization "Swimming" implemented in the educational process various systems for transmitting online and / or offline educational data through the educational content management system (LMS platform - Moodle).

It was decided to carry out the study, the aim of which was, without stopping the educational process in the conditions of an extreme transition to distance learning, to develop an electronic course. It was necessary to fill it with elements, to determine interaction with students and feedback for obtaining certification in the discipline. The study involved 207 first - third-year students of various specialties from the Institute of mining, geology and geotechnology, the Institute of non-ferrous metals and materials science, and the Institute of business process management at Siberian Federal University. $49.7 \%$ of them are first-year students, $26.1 \%$ of them are second-year students and $24.2 \%$ are third-year students. The study was carried out in March - June 2020.

Such research methods as analysis of scientific and methodological literature, open data on distance learning in Russian universities, analysis of the results of interim assessment, and a survey of students were used. As for the survey of students, it was carried out with a help of a questionnaire on the Google platform.

Using the example of the sport specialization "Swimming", we are ready to share our experience of introducing distance learning into the educational process in the form of an electronic course placed on the website of Siberian Federal University in the Moodle ecourses system (https://e.sfu-kras.ru/).

\section{Results}

During the study, a preliminary survey of students was carried out to find out degree of implementation of information technologies in the educational process. Systematic work with Internet resources was noted by $91.3 \%$ of first-year students, $96.3 \%$ of second-year students, $98 \%$ of third-year students.

In this article, a fragment of the implementation of educational activities in the discipline "Applied physical education and sports" for first - third-years students of full-time education is proposed. It is presented by the example of the direction chosen by students for preparation of the sport specialization "Swimming" in electronic courses:

- "Swimming. Full-time education. First year of study" (https://e.sfukras.ru/course/view.php?id=27571);

- "Swimming. Full-time education. Second year of study"(https://e.sfukras.ru/course/view.php?id=27572); 
- "Swimming. Full-time education. Third year of study" (https://e.sfukras.ru/course/view.php?id=27573).

The purpose of this stage of the e-course implementation is the optimal preservation of the student's physical activity during the period of online learning.

The university curriculum included physical education classes twice a week. This schedule was maintained for the period of online learning. Students were able to set aside time every day to maintain physical activity.

The structure of the electronic course of the sport specialization "Swimming" (by the example of one semester) included three interrelated sections:

\section{theoretical}

This section included interactive lectures with control questions of specialization topics: "Safety requirements for organizing and giving swimming classes" (4 points); "General characteristics, classification and features of swimming" (10 points); "Physical properties of water" (20 points). Students could receive a maximum of 34 points for the theoretical section.

\section{Methodical and practical}

This section included tasks of the sport specialization with video reports about on the performance of complexes of physical exercises: "Dry swimming, warm-up activity, 8 exercises of general physical training" "Exercises for swimming and development of flexibility". Students were advised to do the exercises at least 3-4 times a week. The tasks were rated at 2-4 points.

\section{practical}

University teachers developed the "Universal Physical Pause Complex" for daily performance. It consisted of 9 exercises lasting 7-10 minutes. These exercises were performed at the students' workplace. This complex is aimed at maintaining physical performance during the academic day. It is recommended to be performed every 2-3 hours of static work.

Monitoring of the state of health and physical condition was carried out using selfcontrol diaries. The diary included a subjective assessment of well-being, sleep, nutrition, desire to take exercises; indicators of heart rate (HR), respiratory frequency (RF), and blood pressure (BP) at rest, immediately after the exercises, and these indicators after the classes; and also the recovery time of heart rate to the original; time spent on the class or the number of exercises performed; intensity of classes (high, medium, low), as well as the type of activity: cardio training, strength, stretching, parterre gymnastics, dry swimming exercises and elective exercises.

Seven tasks of "Self-Control Diary Report" were scheduled for the semester. The diary was monitored every two weeks. The student received 2 points for keeping a diary and a short analysis. The total score for this assignment in the semester was 14 points. The maximum score for the semester is 54 points, in general for the course - 100-110 points.

The electronic course made it possible to monitor the activity of students within the course (for example, whether a lecture was learnt, whether a video report was sent to a practical task). The video report, as a distance learning assignment, was offered to students for the first time. The mobility and effectiveness of communication between a university teacher and a student allowed university teachers to respond to more than 1000 personal messages, to activate students with weakened internal motivation.

Analysis of the results of the interim assessment in "Applied physical education and sports" revealed a high percentage of academic progress of 1-3 years students who expressed a desire to engage in swimming (Table 1).

Table 1. Results of the interim assessment of students 


\begin{tabular}{|c|c|c|c|c|}
\hline $\begin{array}{c}\text { Year of } \\
\text { study }\end{array}$ & Number & \multicolumn{2}{|c|}{ Results of the interim assessment } & $\begin{array}{c}\% \text { Academic } \\
\text { progress }\end{array}$ \\
\hline & & passed & not passed & \\
\hline 1 & 103 & 91 & 12 & 88.3 \\
\hline 2 & 54 & 50 & 4 & 92.8 \\
\hline 3 & 50 & 46 & 4 & 92 \\
\hline
\end{tabular}

Thus, the academic progress of the 1 -st year students was $88.3 \%$, the 2 -nd year students $-92.8 \%$, the 3 -d year students $-92 \%$.

At the end of semester the carried out survey of students revealed that $51.6 \%$ of respondents did not change the level of motivation to study within the distance format, $25.3 \%$ of respondents increased it, and $23.2 \%$ of respondents decreased it. The study showed that $53.7 \%$ of respondents did not experience any negative changes in well-being, $15.6 \%$ of respondents recorded a decline in mood, $28.1 \%$ of students noted sleep disturbances, only positive changes in well-being were experienced by $26 \%$ of students. $59.4 \%$ of students performed the instruction of university teachers to use a physical education break between classes when they worked on the computer, $65.6 \%$ of respondents did their morning exercises.

During the investigation it was found that $44.8 \%$ of students faced technical problems in the process of distance learning (the need to have access to the Internet $-18.8 \%$; poor Internet speed $-19.8 \%$; technical interruptions at the time of completing assignments $4.4 \%$; insufficient knowledge of PC $-1.8 \%$ ). As for $55.2 \%$ of respondents, they indicated the absence of problems. At the same time, $64.6 \%$ of students would like to return to full time form of study, and $35.4 \%$ of respondents preferred to continue distance learning. Also, students left their wishes for improving the quality of the e-course material provided by university teachers. They asked for more exercise time, more creative assignments, and fewer video recording assignments.

\section{Discussion}

In the modern dynamically developing world, one of the important tasks of higher education is to ensure access to education. It has to depend on neither various life situations nor emergency situations of forced transition to the distance learning format (for example, during a quarantine period).

Analysis of foreign and Russian experience in the transition to distance learning in pandemic determines the relevance of the undertaken study. Many foreign scientists noticed that all occurring in the education system all over the world is a very important forced experiment. This situation is absolutely massive, covering the education system in almost all countries. It can be shown by way of example of equipping with computers (according to Organization for Economic Co-operation and Development (OECD), in Denmark, Slovenia, Norway, Poland, Lithuania, Iceland, Austria, Switzerland and the Netherlands more than $95 \%$ of students have got computers for work; in comparison, in Indonesia $34 \%$ of students have got computers [9]).

The pandemic has greatly affected higher education in one of the regions of China Hong Kong.J. Jung and his colleagues [10] believe that with the transition to distance learning only $26 \%$ of students consider the completed online learning to be quite successful, compared to in person learning; $60 \%$ of students believe the effectiveness of online learning to be lower. As for university teachers, they consider their motivation to be underestimated, as they sometimes could not see the students when studying online. 
In several countries, such as Brazil, the pandemic has revealed weaknesses in the education system. P.F.R. Miranda [11] believes that the pandemic has reduced the students achievement in both schools and universities. And this has increased social vulnerability. The same situation is developing in educational institutions in India. Experts notice that there are no digital learning systems and technical equipment for students [12]. Experts in Nigeria also note the enormous impact of the pandemic [13]. They indicate that the student achievement and learning ability are reduced since students are deprived of the opportunity to learn.By the example of Arab universities, Z. Lassoued [14] and his colleagues notice that currently distance education has become an urgent need for universities under forced emergency conditions. This form of study combines all existing technologies and creates flexibility in the learning environment, and it promotes quality education and improves the ranking of universities. Also, in Arab universities, old and modern forms of distance education were combined. For example, in universities in Algeria, Egypt and Palestinestudents are taught with a help of radio and television.

J.L.D. Anoba and M.B. Cahapay [15] note that in 2020 the Philippine Ministry of Education announced the planned opening of training sessions and possible actions to introduce blended learning: traditional and online learning, despite the fact that the country continues to fight the COVID-19 pandemic.

At the beginning of the COVID-19 pandemic S. Alqabbani together with colleagues [2] carried out a cross-sectional study at Princess Nourah Bint Abdulrakhman University, Riyadh, Saudi Arabia. The aim of this study was to reveal the readiness of university teachers to switch to full distance learning in emergency situations. The results of the study showed that only $44.9 \%$ of university teachers are ready for the emergency distance learning.

Scientists from the Philippines, Rome Moralista and his colleague [16], also surveyed teachers of local colleges and universities. The study showed that teachers were generally unsure whether they supported online education and how existing difficulties and problems affected online education.

The American scientist Santanu De [17] suggests that the use of web mobile applications and other digital tools at universities will be able to threaten the quality of education in the future. In their work W. Cao and colleagues [18] notice that the isolation caused by COVID-19 not only make difficulties for attendance, learning and acquisition of new knowledge among many students, but also it caused psychological stress and anxiety for both students and university teachers. Scientists from the UK, headed by Thathsara D. Maddumapatabandi [19], note the rapid technical growth of information technologies, developing in step with the time in the online education system. But at the same time, they are afraid of the occurrence of negative problems which can negatively affect the selfdiscipline of students.

The Russian group of scientists, headed by V.A. Zernov [20], believes that the pandemic has given a serious impetus in order to comprehend the most important aspects of the life of the world society, to analyze the strengths and weaknesses of online education, the opportunities and threats for obtaining high-quality training of future specialists.

We agree with the opinion of I.P. Shchenkova and D.N. Pryanishnikova [21] that the pandemic revealed a number of problems faced by students in the process of distance learning. These are such problems as a lack of computer equipment, both among students and university teachers, as well as a lack of understanding of the online methods by which classes need to be taught. First of all, this affected so-called "old school" university teachers.

The world has held a course for digitalization of education. Russia keeps in step with technological progress. Digital technologies and tools are introduced at universities, and it expands the possibilities of using interactive teaching methods [7]. 
E. Nordmann [22] and colleagues note that one of the most important rules of distance learning is asynchronous contact and "university teacher - student" communication. And this rule is one of the conditions for providing students with educational materials in many disciplines, including "Applied Physical Education and Sports", when students can practice according to their own schedule.

Over a period of several years Siberian Federal University has been implementing part of the programs in the format of distance learning for students by correspondence and parttime forms of education, including in the disciplines "Physical culture and sports" and "Applied physical education and sports". Electronic courses have already been developed in the above-mentioned disciplines for distance learning. Over the last 5 years, more than 2000 students have taken these courses [23]. For the first time at the Department of Physical Culture, electronic courses have been developed and implemented for full-time students in the discipline of applied nature - "Applied Physical Education and Sports". The experience of our colleagues is expressed in a number of papers [24].

\section{Conclusion}

The obtained results of the carried out research do not contradict the results of the published papers of scientists from different countries. However, our practical experience of introducing distance learning into the educational process has shown that there are problems. The thing is, the university teachers in the field of physical education are not fully prepared for the transition to digital technologies in the educational process. This unpreparedness manifests itself both in technical support and in psycho-emotional mood. At the same time, the students, using the electronic format in teaching, participated in our study and showed satisfactory results of interim assessment. It should be noted that work on the electronic courses "Swimming. Full-time education. First year of study", "Swimming. Full-time education. Second year of study", "Swimming. Full-time education. Third year of study" has not been completed yet. In future it is planned to develop methodological support, improve the methodological-practical and practical sections. Therefore, despite the relevance of the distance learning format in the current environment, e-learning systems cannot be considered as a full-fledged alternative to full-time education. The above is also true of the considered practical discipline. The presented study is not intended to be an exhaustive solution to the problem of distance learning in the discipline "Applied physical education and sports". It is supposed that some aspects of this paper will be able to be included in a new research.

\section{References}

1. T.S. Tsener, A.V. Oshkina, International Journal of Humanities and Natural Sciences 5-3 (44), 170-177 (2020). doi: 10.24411/2500-1000-2020-10576

2. S. Alqabbani, A. Almuwais, N. Benajiba, F. Almoayad, Readiness towards emergency shifting to remote learning during COVID-19 pandemic among university instructors, Article reuse guidelines: sagepub.com/journals-permissions. (2020). doi: 10.1177/2042753020981651

3. D.A. Shtykhno, L.V. Konstantinova, N.N. Gagiev, Open education 24 (5), 72-81 (2020). doi:dx.doi.org/10.21686/1818-4243-2020-5-72-81

4. E.V. Frolova, O.V. Rogach, T.M. Ryabova, Science and Education Perspectives 6 (48), 78-88. (2020). doi: 10.32744/pse.2020.6.7 
5. N.V. Kuznetsov, E-Management 1, 19-25 (2019). doi: 10.26425/2658-3445- 2019-119-25

6. S.N. Vodolad, M.P. Zaikovskaya, T.V. Kovaleva, G.V. Savelieva, Electronic scientific journal of Kursk State University 1 (13), 129-138. (2010).

7. A.V. Ageevets, V.Yu. Efimov-Komarov, L.B. Efimova-Komarova, E.A. Nazarenko, M.V. Puchkova, Scientific notes of P.F. Lesgaft university 182, 3-10 (2020).

8. E.V. Grunt, E.A. Belyaeva, S. Lissitsa, Prospects for science and education 5 (47), 45 58 (2020). doi: 10.32744 / pse.2020.5.3

9. Almanthari Mailiza, A. Maulina, S. Bruce, Secondary School Mathematics Teachers' Views on E-learning Implementation Barriers during the COVID-19 Pandemic: The Case of Indonesia, EURASIA Journal of Mathematics, Science and Technology Education 16 (7), (2020). doi.org/10.29333/ejmste/8240

10. J. Jung, H. Horta, G.A. Postiglione, Studies in Higher Education 46 (7), (2021). doi.org/10.1080/03075079.2020.1859685

11. P.F.R. Miranda, COVID-19: A new crisis that reinforce inequality in higher education in Brazil. doi: 10.1590/SciELOPreprints. 1341

12. M. Goplani, A. The Online Journal of Distance Education and e-Learning 8 (3), 157163 (2020).

13. A.T. Agbele, E.A. Oyelade, Asian Journal of Education and Social Studies 13 (1), 2635 (2020).

14. Z. Lassoued, M. Alhendawi, R. Bashitialshaaer, Educ. Sci. 10 (9), 232 (2020). doi.org/10.3390/educsci10090232

15. J.L.D. Anoba, M.B. Cahapay, International Journal of Teaching, Education and Learning 4 (2), 295-316 (2020). doi.org/10.20319/pijtel.2020.42.295316

16. R. Moralista, R.M. Oducado, Universal Journal of Educational Research, Horizon Research Publishing Corporation (HRPUB) 8 (10), 4736-4742 (2020). doi: 10.13189/ujer.2020.081044

17. S. De, Royal Book Publishing 85-93 (2020). doi.org/10.26524/royal.37.6

18. W. Cao, Z. Fang, G. Hou, M. Han, X. Xu, J. Dong, J. Zheng, Psychiatry Research 287, 112934 (2020). doi.org/10.1016/j.psychres.2020.112934

19. T.D. Maddumapatabandi, K.A.A. Gamage, Journal of Applied Learning \& Teaching 3 (2) (2020). doi.org/10.37074/jalt.2020.3.2.20

20. V.A. Zernov, A.Yu. Manyushis, A.Yu. Valyavsky, N.V. Uchevatkina, Scientific works of Russian VEO 223, 304-322 (2020). doi: 10.38197/2072-2060-2020-223-3-304-322

21. I.P. Shchenkova, D.N. Pryanishnikova, International Journal of Humanities and Natural Sciences 5-3 (44), 190-193 (2020). doi:10.24411/2500-1000-2020-10580

22. E. Nordmann, C. Horlin, J. Hutchison, Jo-Anne Murray, L. Robson, M.K. Seery, J.R.D. MacKay, PLoSComput Biol 16 (10). doi.org/10.1371/journal.pcbi. 1008242

23. E.A. Dergach, O.B. Savyalova, N.A. Bryukhanova, Bulletin of Krasnoyarsk State Pedagogical University named after A.P. Astafyev 2, 103-110 (2019). doi: 10.25146/1995-0861-2019-47-1-127

24. A.Y. Osipov, T.I. Ratmanskaya, E.A. Zemba, V. Potop, M.D. Kudryavtsev, R.S. Nagovitsyn, Physical education of students 1, 20-27 (2021). doi:10.15561/20755279.2021.0103 